\title{
Finansal Krizlerin Belirleyenleri ve Öngörülebilirliği: Türkiye Üzerine Bir Uygulama
}

\author{
Determinants of Financial Crises and the Predictability: A Case Study for Turkey
}

\author{
Muhammet Ali AVCI ${ }^{1}$, N.Oğuzhan ALTAY²
}

\begin{abstract}
ÖZET
Bu çalışmanın amacı, 1990:01-2009:07 dönemi Türkiye'de yaşanan finansal krizlerin öngörülebilirliğini ve bu krizlerin öncü göstergelerini Regresyon Ağaçları ve Markov Rejim Değişimi modellerini kullanarak incelemektir. Uygulama sonuçlarına göre regresyon ağaçları modelinde, para piyasası baskı endeksi, yurtiçi kredilerin endüstriyel üretime oranı, M2/rezervler enflasyon, Markov rejim değişimi modelinde ise ticaret haddi, ticaret dengesi, enflasyon ve M2/rezervler gibi göstergeler finansal krizleri öngörmede başarılı bulunmuşlardır. Bu kapsamda Türkiye'de, 1994 ve 2001 yıllarında yaşanılan krizler öngörülürken, 2008 Küresel Finansal Krizi öngörülememiştir.
\end{abstract}

Anahtar Kelimeler: Finansal kriz, öngörülebilirlik, regresyon ağaçları, markov rejim değişimi

\section{GíRiş}

Doksanlı yıllardan itibaren dünyanın farklı bölgelerinde yaşanan finansal krizlerdeki artışa paralel olarak, geliştirilen finansal kriz modellerinin sayısı da artmıştır. Geliştirilen modellerin temel amacl, finansal krizlerin oluşumunda etkin olan faktörleri belirlemek ve bu krizlerin öngörülebilmesini sağlamaktır. Finansal krizlerin öngörülmeye çalışılması, kriz maliyetlerinin en aza indirilmesi yanında olası krizlerin önlenmesi açısından da önem taşımaktadır. Uygulamalı finansal kriz modelleri literatürde genellikle standart modeller ve bu modellere alternatif olarak geliştirilen yeni modeller başıkları altında incelenmektedir. Standart modeller, sinyal yaklaşımı (Kaminsky vd., 1998) ve sınırlı bağımlı regresyon (LogitProbit) modelleridir (Frankel ve Rose, 1996). Diğer yandan son yıllarda finansal krizlerin öngörüsünde çok sayıda analiz tekniği kullanılmaktadır. Örneğin bu makalede kullanılan Markov rejim değişimi (MRD) modeli (Hamilton, 1989) ile sınıflama ve regresyon ağaçları (Classification and Regression Trees-CART) modeli (Breiman, 1984) sözü edilen modellerdendir. Bunların dışında, yapay sinir ağları modeli (Nag ve Mitra, 1999), Fisher diskriminant analizi (Burkart ve Coudert, 2000) ve sınırlandırılmış VAR modelinden de (Krokoska, 2000) söz edilebilir.

\begin{abstract}
The aim of this study is to analyze the predictability of financial crises and to determine the leading indicators of these crises in the period of 1990:01-2009:07 for Turkey by using Regression Trees and Markov Regime Switching models. According to the results, in Regression Trees model for predicting financial crises the most significant indicators are; money market pressure index, rate of industrial production to domestic credit, M2/Reserves, inflation, on the other hand in Markov Regime Switching model these indicators are terms of trade, balance of trade, inflation and M2/Reserves. In this context, while the financial crises experienced in Turkey in 1994 and 2001 are successfully predicted, 2008 global financial crisis could not be predicted.
\end{abstract}

Keywords: Financial crisis, predictability, regression trees, markov regime switching

Çalışmanın temel amacı CART ve MRD modellerini kullanarak 1990:01-2009:07 döneminde Türkiye'de yaşanan finansal krizlerin öncü göstergelerini belirlemek ve bu krizlerin öngörülebilirliğini analiz etmektir. Bu bağlamda çalışma iki açıdan literatüre katkıda bulunmaktadır. Bunlardan birincisi iki farklı yöntemin karşılaştırmalı bir biçimde kullanılmasıdır. Konuya ilişkin araştırmalarda bu yöntemlerin birlikte kullanıldığı çalışma sayısının sınırlı olduğu görülmüştür. Özellikle CART modeli kullanılarak sadece Türkiye'ye ilişkin bir çalışmaya tarafımızca rastlanmamıştır. Diğer taraftan literatür taramalarında krizlerin öngörülebilirliği ile ilgili çalışmaların büyük çoğunluğu 2008 Küresel Finansal Kriz'i öncesi dönemi kapsamaktadır. Bu nedenle çalışmanın literatüre ikinci katkısı 2008 Küresel Finansal Krizi'ni kapsamasıdır. Çalışma altı bölümden oluşmaktadır. İkinci bölümde 1990:012009:07 dönemi Türkiye'de yaşanan finansal krizler incelenmiştir. Üçüncü bölümde CART ve MRD modelleri ile ilgili yapılan literatür taramasına, dördüncü bölümde çalışmada kullanılan model, veri kaynakları ve değişkenlere, beşinci bölümde uygulamalara yer verilmiş, altıncı bölümde ise uygulamalara ilişkin genel değerlendirmeler aktarılmıştır.

\footnotetext{
' Dr., Pamukkale Üniversitesi, İktisadi ve İdari Bilimler Fakültesi, İktisat Bölümü, malia@pau.edu.tr

${ }_{2}^{2}$ Prof.Dr., Ege Üniversitesi, İktisadi ve İdari Bilimler Fakültesi, İktisat Bölümü, oguzhan.altay@ege.edu.tr
} 


\section{1990-2009 DÖNEMI TÜRKIYE'DE YAŞANAN KRIZLER}

İncelenen dönem için Türkiye ekonomisine bakıldığında istikrarsız bir makroekonomik çevrenin, bankacılık sisteminin kırılganlığının ve zayıf bankacılık denetiminin yaşanan finansal krizlerde ortaya çıkan ortak faktörler olduğu görülmektedir (Kasman, 2003: 84). Türkiye ekonomisi 1988-1993 döneminde devalüasyon beklentisi ve reel döviz kurundaki artışlar gibi iç, körfez savaşı gibi dış piyasalardaki konjonktürel belirsizliklerden kaynaklanan istikrarsız bir büyüme yapısına sahip olmuştur. 1988 ve 1989 yıllarında yaşanan stagflasyon sonucu çıkarılan 32 sayılı KHK ile sermaye hareketleri ve mali piyasalar makroekonomik istikrarın sağlanmadığı bir ortamda aşırı ölçüde serbestleştirilmiştir. Türkiye'de 1989'dan sonra kamu gelir gider dengesi ciddi bir biçimde bozulmuş, artan kamu harcamalarının finansmanı için giderek daha fazla oranda merkez bankası kaynaklarına ve vadeleri giderek kısalan iç ve dış borçlanmaya başvurulmuştur (Altay, 2002: 17-20). 1993 yılı ikinci yarısında faiz oranları aşağı çekilmek istenmiş ancak mevduattan ayrılan likit fonlar, borsa ve döviz piyasasına yönelerek döviz kurlarının yükselmeye başlamasına neden olmuştur. Bu ortamda uluslararası kredi kuruluşlarının Türkiye'nin kredi notunu düşürmeleri, finansal piyasadaki paniği artırmış ve dövize hücumun başlamasına yol açmıştır. Merkez bankası, döviz kurlarını korumada başarılı olamamış ve 5 Nisan 1994 istikrar kararlarıyla sonuçlanan 1990 sonrasının ilk ve en büyük krizi meydana gelmiştir (Şahin, 2002:213-235).

1994 Krizi sonrası alınan kararlar ve izlenilen politikalarla Türkiye ekonomisi yaklaşık beş yıl iç talep canlılığına dayalı, tasarruf açığı süren, istikrarsız büyüyen bir görünüm sergilemektedir. 1997 GüneyDoğu Asya ve 1998 Rusya krizlerinin getirdiği dışsal etkiler ve içeride biriken sorunlar Türkiye ekonomisinin 1998 yılının ikinci yarısından itibaren yeniden bir ekonomik krize sürüklemiştir. Bu gelişmeler üzerine IMF ile Haziran 1998'de Yakın İzleme AnlaşmaSı, Aralık 1999'da da üç yıllık bir stand-by anlaşması imzalanmıştır. Anlaşma kapsamında Ocak 2000'de Enflasyonla Mücadele Programı (EMP) uygulanmaya başlanmıştır (Altay, 2011:22-25). EMP'nin uygulanmasına rağmen kriz belirtileri Temmuz 2000'de hissedilmeye başlanmıştır. Kamu harcamaları azaltılamamış, mali yapıları bozulan bankalar ciddi bir denetim olmadan faaliyetlerini sürdürmüş ve yapısal reformlar gerçekleştirilememiştir. Bu olumsuzluklar likidite krizi şeklinde de ifade edilen Kasım 2000'de ülkeden sermaye çıkışını uyarmış ve borsa endeksi gerilerken faiz ve döviz kurları yükselmeye başlamıştır. Türkiye ekonomisi Şubat 2001 'de gerçek anlamda bir krizle karşı karşıya kalmıştır. Bu gelişmeler sonucunda IMF ile yapılan stand-by anlaşması doğrultusunda $14 \mathrm{Ni}$ san 2001'de güçlü ekonomiye geçiş programı (GEGP) açıklanmıştır (Şahin, 2002:243-254; Özatay, 2011:537542).

2002 yılında tek başına iktidara gelen AK Parti hükümeti bu programa sahip çıkmış ve IMF'le birlikte sözü edilen programı 2008 yılına kadar sürdürmüştür. Türkiye ekonomisi Küresel Finansal Kriz'in meydana geldiği 2008 yılına kadar geçen 2002-2007 döneminde gerek tek parti hükümetiyle yönetilmesi, gerekse DSP-MHP-ANAP Koalisyon Hükümeti'nin GEGP'na uyması ve uluslararası piyasalardaki olumlu gelişmelerinde yardımıyla göreceli olarak istikrarlı bir dönem geçirmiştir. Türkiye 2008 küresel finansal krizini, finansal piyasalarının küçük ve 2001 krizi sonrasında getirilen bankacılık sisteminin denetim ve gözetiminin güçlü, konut kredilerinin ve finansal ürün çeşitliliğinin oldukça az ve basit olması gibi nedenlerle finans sektöründe sınırlı oranda hissetmiştir. Ancak, dünya ekonomisinde ve özellikle 2008'de toplam ihracatının \% 48'ini gerçekleştirdiği AB ekonomilerindeki büyüme oranı ve dış ticaret hacminin hızla düşmeye başlaması, Türkiye'nin krizi ticaret kanalı vasıtası ile reel sektöründe şiddetli hissetmesine neden olmuştur. İç ve dış talepteki gerileme, şirketlerin cirolarını düşürürken stoklarının artmasına neden olmuştur. Artan belirsizlik ortamı ve güven kaybı kredi mekanizmasının çalışmasını engellemiş, bu durum reel kesimin borçlanma imkânlarını sınırlarken borçlanma maliyetlerinin de önemli ölçüde artmasına yol açmıştır (Togan, 2009:7-23; Aydoğuş, 2009:27-47).

\section{LITERATÜR TARAMASI}

CART ve MRD modelleri finansal krizlerin öngörüsünde kullanılan yeni modellerden olup, bu modellere ilişkin literatür sınırlıdır. Literatürdeki ulaşılabilen çalışmalardan bazıları şunlardır:

Gosh ve Gosh (2003), çalışmada gelişmiş ve gelişmekte olan 42 ülkenin 1987-1999 dönemi analiz edilerek, bu ülkelerde meydana gelen ödemeler dengesi krizleri öngörülmeye çalışılmıştır. Bağımlı değişken olarak 52 ödemeler dengesi krizi bulunmaktadır. Bağımsız değişkenler 22 göstergeden oluşmaktadır. Çalışma sonuçlarına göre GSYiH'nın en azından \%3 küçüldüğü derin finansal krizlerde yapısal faktörlerin en az ekonomik faktörler kadar önemli rol oynadığı sonucuna varılmış ve yapısal kırılganlık ile makroekonomik dengesizlikler arasında karmaşık bir etkileşim olduğu belirtilmiştir. 
Chamon vd. (2007), 49 ülkede 1994-2005 döneminde meydana gelen sermaye hesabı krizlerini CART modelini kullanarak öngörmeye çalışmışlardır. IMF ekonomistlerinin yardımı ile çalışmada kullanılacak final kriz dönemleri belirlenmiştir. Çalışmada bağımsız değişkenler olarak dış, mali, finansal, şirket göstergeleri ana başııkları altında 5'er gösterge kullanılmıştır. Ülke bazlı analizlerde ise bu göstergelere ek olarak iki makroekonomik ve iki global talep şartlarını gösteren gösterge kullanılmıştır. Çalışma sonuçlarına göre sermaye hesabı krizlerini öngörmede en başarılı göstergeler olarak, uluslararası rezervler, cari işlemler dengesi ve kısa dönem dış borçlar bulunmuştur.

Davis ve Karim (2008), çalışmalarında küresel finansal krizi öngörmeye çalışmışlardır. 105 ülkenin 1979-2003 dönemi logit ve CART modelleri kullanılarak analiz edilmiştir. Bağımlı değişken olarak Demirgüç ve Detragiache (2005)'in çalışmasındaki 72 finansal kriz dönemi, bağımsız değişken olarak ise farklı gruplarda toplam 12 gösterge kullanılmıştır. Logit modeli sonucuna göre reel GSYiH, ticaret hadleri, M2'nin uluslararası rezervlere oranı krizleri açıklamada anlamlı bulunan göstergelerdir. CART modelinde ise reel faiz oranları, kişi başına GSYiH, devalüsyon oranı ve enflasyon kriz olasılığını artıran göstergelerdir.

Duttagupta ve Cashin (2008), çalışmalarında 50 gelişmekte olan ülkenin 1990-2005 dönemini CART modeli ile analiz etmişlerdir. Bağımlı değişken olarak kullanılan 38 kriz dönemi ve bağımsız değişken olarak kullanılan 18 farklı gösterge literatürdeki diğer çalışmalardan elde edilmiştir. Çalışma sonucuna göre finansal krizleri açıklamada en anlamlı bulunan göstergeler faiz farklıığı, enflasyon, mevduatlardaki dolarizasyon, bankaların likidite yetersizliği ve bankaların karlılığındaki düşmedir. Bunun yanında krizlerin finansal ve makroekonomik göstergeler arasındaki karmaşık ilişkiler tarafından tetiklendiği belirtilmiştir.

Abiad (2003), çalışmasında kriz yaşayan beş Güney-Doğu Asya ülkesinin 1972-1999 dönemini MRD modeli ile analiz etmiştir. Bağımlı değişken olarak nominal döviz kurunun, uluslararası rezervlerin ve faiz oranlarının aylık değişimlerinden elde edilen kriz değişkeni kullanılmıştır. Bağımsız değişkenler olarak makroekonomik dengesizlikler, sermaye akımları ve finansal kırılganlık ana başlıkları altında toplanan 22 gösterge kullanılmıştır. Model standart sinyal yönteminden hem mevcut krizleri öngörmesi hem de daha az yanlış sinyal vermesi açısından üstün bulunmuştur. Çalışma sonucuna göre iki önemli bulgu ortaya çıkmıştır. Bunlardan birincisi var olan modellerin göz ardı ettiği döviz kuru dinamiklerinin modele katılması ve anlamlı bulunmasıdır. İkincisi ise farklı ülkeler için farklı göstergelerin kullanılması ve göstergelerin performanslarının ülkeden ülkeye farklılaşmasıdır.

Mariano vd. (2004), çalışmalarında MRD modeli ile finansal krizi öngörmeye çalışmışlardır. Türkiye'nin 1954-2002 dönemi aylık ve haftalık veriler kullanılarak analiz edilmiştir. Kriz değişkeni olarak nominal TL/Dolar kuru kullanılmıştır. Çalışma sonuçlarına göre bağımsız değişken kullanılmadan yapılan tahminde 1960, 1971 ve 1980 devalüasyonları başarı ile öngörülmüştür. Daha sonra model 1981-2002 dönemi için bağımsız değişkenler olarak reel döviz kuru, uluslararası rezervler ve yurt içi kredilerin mevduatlara oranı eklenerek tahmin edilmiştir. 1994 ve 2001 krizleri model yardımıyla öngörülmüştür.

Knedlik (2007), çalışmasında sinyal, probit ve MRD modellerini kullanarak Güney Afrika'nın yaşadığı finansal krizleri öngörmeye çalışmıştır. Çalışmada kullanılan bağımlı değişken döviz kuru, faiz oranları ve uluslararası rezervlerden oluşan döviz kuru baskı endeksi, bağımsız değişkenler de 15 farklı göstergedir. Çalışmanın sonuçlarına göre sinyal yaklaşımında 1996 ve 1998 krizleri için güçlü sinyaller alınırken, probit modelinde 1996, 1998 ve 2001 yılları, MRD modelinde ise 1996, 1998, 2001 ve 2006 yılları kriz dönemi olarak öngörülmüştür. Çalışmada krizlerin öngörüsünde tek yöntemle yetinilmemesi gerektiği önerilmiştir.

Brunetti vd. (2007), çalışmalarında Malezya, Filipinler, Singapur ve Tayland'ın 1984-2001 dönemini aylık veriler kullanılarak MRD modeli ile analiz etmişlerdir. Kriz dönemleri yüksek döviz kuru değişimleri olarak tanımlanmıştır. Çalışma sonuçlarına göre reel efektif döviz kuru bütün ülkeler için çok yüksek açıklayıcı güce sahiptir. Bunun yanında M2'nin uluslararası rezervlere oranı, borsa endeksi getirileri ile bankacılık sektörü endeksi getirileri ve oynaklığı anlamlı ve modelin performansını geliştirici göstergeler olarak bulunmuştur.

Çeşmeci ve Önder (2008), çalışmalarında sinyal yaklaşımı, yapısal model ve MRD modeli olmak üzere üç model kullanmışlardır. Çalışmada Türkiye'nin 1992-2004 dönemi aylık veriler kullanılarak analiz edilmiştir. Bağımsız değişkenler olarak çeşitli gruplar altında elli sekiz gösterge kullanılmıştır. Kriz değişkeni olarak döviz kurundan, faiz oranlarından ve uluslararası rezervlerden döviz piyasası baskı endeksi oluşturulmuştur. Çalışma sonuçlarına göre para piyasası baskı endeksi ve reel sektör güven endeksi üç 
yöntemde de en anlamlı göstergeler olarak bulunmuştur. Kamu borcu sinyal yönteminde, bütçe dengesinin GSYIH'ya oranı yapısal ve MRD modellerinde en anlamlı göstergeler olarak bulunmuşlardır. Bunun yanında bankacılık krizlerinin para krizlerine yol açtığının söylenebileceği belirtilmiş, Nisan 1994, Kasım 2000 ve Şubat 2001 krizleri başarı ile öngörülmüştür.

\section{MODEL, VERI KAYNAKLARI VE KULLANILAN DEĞIŞKENLER}

\subsection{Regresyon Ağaçları Modeli}

Breiman (1984) tarafından geliştirilen CART modeli gerek kategorik, gerekse sürekli değişkenler arasındaki ilişkileri ortaya çıkarmak için son zamanlarda sıkça kullanılan parametrik olmayan bir tahmin yöntemidir. Tahmin edilmek istenen bağımlı değişkenin kategorik olması durumunda sınıflama ağaçları kullanılırken sürekli olması durumunda regresyon ağaçları kullanılmaktadır. CART analizinde ağaçlar her biri sağ ve sol olmak üzere iki kısma ayrılan düğümlerden ve bu düğümleri birbirine bağlayan dallardan meydana gelmektedir. Ağaçlarda 3 tür düğüm bulunmaktadır. Bunlar başlangıç (kök), ara ve yaprak düğümdür.

CART analizi öğrenme ve doğruluk sınaması olarak iki ana aşamadan oluşmaktadır. Öğrenme aşamasında veri setinde öğrenme verisi olarak ayrılan tüm veriler başlangıçta kök düğümde toplanmakta ve CART algoritması tarafından analiz edilmektedir. Algoritmanın yaptığı işlem, bir düğümü iki alt düğüme ayırırken öncelikle ayırmanın gerekli olup olmadığını daha sonra ise ayırmanın hangi açıklayıcı değişken üzerinden yapılacağını belirlemektedir. Bu amaçla o kök düğümde yer alan verileri mümkün olan en homojen iki alt düğüme ayıran açıklayıcı değişken ve bu değişken için bir ayırma eşik değeri belirlenmektedir. Daha sonra bu düğümdeki veriler belirlenen bu açıklayıcı değişkenin aldığı değerlere göre eşik değerinden küçük veya eşit olanlar sol alt düğüme, diğerleri ise sağ alt düğüme gidecek şekilde ayrılmaktadır. Ayırma işlemi kök düğümden başlayarak dügüumler yeterli homojenliğe ulaşıncaya kadar devam etmektedir. Bir düğümün homojenliği safsızlık endeksi ile belirlenmektedir. Safsızlık endeks değeri küçüldükçe homojenlik artmaktadır. Uygulamada en yaygın olarak kullanılan safsızlık endeksleri sınıflama ağaçları için gini ve regresyon ağaçları için LSD (Least Squares Deviation) endeksidir (Nisbet vd., 2009: 139-145; Statsoft, 2011). ${ }^{1}$ CART analizinin ikinci aşaması doğruluk sınamasıdır. Bu aşama sonucunda elde edilen ağaca maksimal ağaç denmektedir. Bu aşamada test verisi olarak ayrılan veri seti maksimal ağaca uygulanarak bağımlı değişken değerleri tekrar tahmin edilmektedir. Daha sonra test verisinin önceden bilinen gerçek değerleri ile tahmin edilen değerleri karşılaştırılarak modelin gerçeğe ne kadar yakın tahmin yapabildiği belirlenmektedir (Breiman, 1984:42). Literatürde basit gerçeklik, çapraz gerçeklik, n-katlı çapraz gerçeklik ve bootstrapping gibi pek çok doğruluk sınaması yöntemi bulunmaktadır (Statsoft, 2011). Öğrenme aşaması sonunda elde edilen maksimal ağaç öğrenme verisi için en doğru ağaç olmasına rağmen oldukça karmaşık bir yapıya sahip olduğu için kullanım açısından uygun değildir. Bu nedenle uygulamada maksimal ağacın budanması ile elde edilen ve çok daha basit bir yapıya sahip olan optimal ağaç kullanılmaktadır. Budamalar sırasında karmaşıklığı uygun bir seviyeye indirirken tahmin gücündeki hata oranını çok fazla artırmayan bir ağaç optimal ağaç olarak tespit edilmektedir. Ağaç modeli oluşturulduktan sonra yeni elde edilen bir verinin bağımlı değişken değeri tahmin edilmek istendiğinde bu veri kök düğümünden itibaren ağaç üzerinde aşağıya doğru sürekli ilerletilerek bir yaprağa ve dolayısıyla bir tahmin değerine ulaşılmaktadır (Breiman, 1984:223).

\subsection{MRD Modeli}

Hamilton (1989, 1990, 1994) tarafından geliştirilen MRD modeli zaman serisi analizlerinde doğrusal olmayan modellerin tahmininde yaygın olarak kullanılmaktadır. MRD modeli, t ve $\mathrm{t}-1$ dönemlerindeki rejimler arasındaki ilişkiyi incelemektedir ve

$$
y_{t}=a_{s_{t}}+x_{t} \beta_{s_{t}}+\varepsilon_{t} \varepsilon_{t} \sim i, i, d, N\left(0 . \sigma_{s, s t}^{2}\right)
$$

şeklinde gösterilmektedir. Formüldeki yt kriz baskı endeksini, xt bağımsız değişkenleri, st rejim değişkenini ifade etmektedir. MRD modelinde rejim değişimi bir olasılık fonksiyonu olarak açıklanmaktadır. Modelde rejim dönemleri tesadüfî bir değişken olan ve direk olarak gözlemlenemeyen st tarafından belirlenmektedir. Bu durumda st rejim değişkeninin alacağı olasılık değeri bir önceki rejim dönemine bağlı olarak;

$$
p\left\{s_{t}=j \mid s_{t-1}=i\right\}=P\left\{s_{t}=j \mid s_{t-1}=i . s_{t-2}=k \ldots .\right\}=p_{i j}(2)
$$

şeklinde gösterilmektedir. Yukarıdaki denklem birinci sıra Markov zincirine uyan rejim i'den rejim j'ye geçiş olasılıklarını göstermektedir. MRD modeli maksimum olabilirlik yöntemi ile tahmin edilmektedir. Tahmin süreci sonunda filtrelenmiş ve öngörülmüş olasılık değerleri elde edilmektedir.

\subsection{Veri Kaynakları ve Kullanılan Değişkenler}

Finansal krizleri öngörebilmek için öncelikle kriz dönemlerinin elde edileceği finansal baskı endeksi- 
nin (FBE) hesaplanması gerekmektedir. Literatürde bu endekslerin hesaplanmasında genelde nominal döviz kuru, faiz oranı ve net uluslararası rezervler kullanılmaktadır. Finansal kriz esnasında çoğunlukla nominal döviz kurunda ve faiz oranlarında önemli miktarda artışlar olurken net uluslararası rezervlerde normalin üzerinde azalışlar meydana gelmektedir. Çalışmada Eichengreen vd. (1995) makalesinde yer alan finansal baskı endeksi (FBE) kullanılmıştır.
Formül aşağıdaki gibidir;

$$
F B E=\left(\frac{\Delta e}{e_{t-1}}\right)-\left[\left(\frac{\sigma \Delta e}{\sigma \Delta r}\right) *\left(\frac{\Delta r}{r_{t-1}}\right)\right]+\left[\left(\frac{\sigma \Delta e}{\sigma \Delta f}\right) * \Delta f\right]
$$

Formüldeki $\Delta \mathrm{e}$, nominal döviz kurundaki değişimi, $\Delta r$ net uluslararası rezervlerdeki değişimi, $\Delta f$ bankalar arası gecelik faiz oranındaki değişimi, $\sigma$ ise standart sapmayı göstermektedir. Formül 3 ile elde edilen FBE şekil 1'de gösterilmiştir.

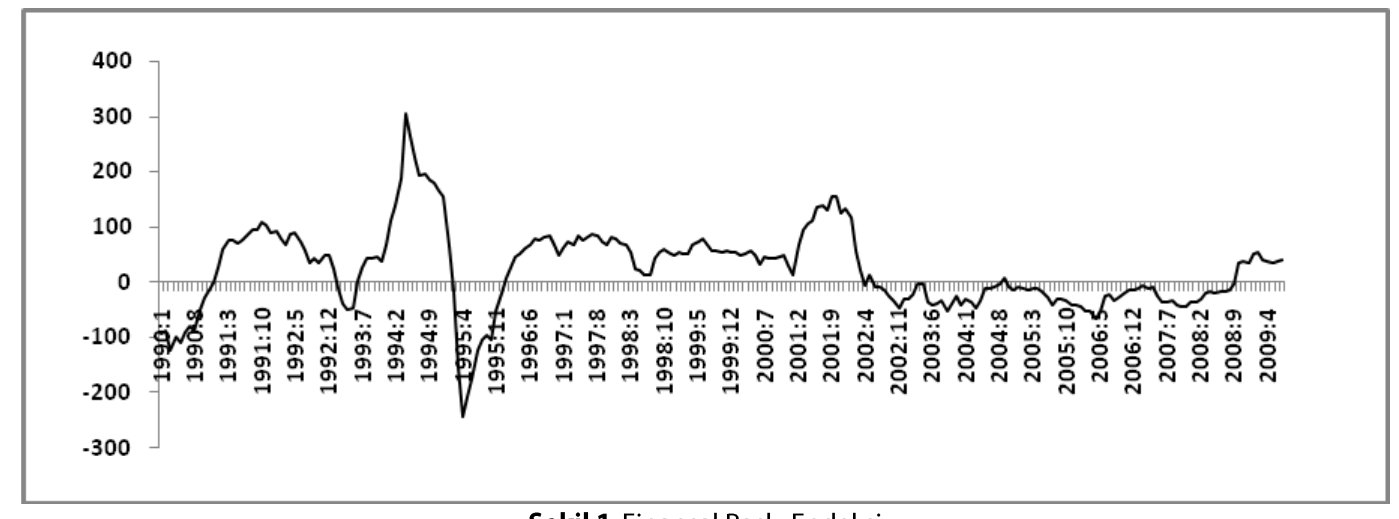

Şekil 1: Finansal Baskı Endeksi

Çalışmada kullanılan göstergelerin seçilirken ilkönce finansal krizlerin öngörüsüyle ilgili uygulamalı çalışmalara ilişkin geniş bir literatür taraması yapılmıştır. ${ }^{2}$ Daha sonra bu çalışmalarda kullanılan göstergelerden en çok kullanılan 15 tanesi seçilmiştir. Seçilen bu göstergeler; endüstriyel üretim, hissen senedi fiyatı, enflasyon, M2 çarpanı, M2/Rezervler, M2/Rezervler düzey, petrol fiyatı, para piyasası baskı endeksi (PPBE), reel döviz kurunun trendden sapması (RDKTS), reel faiz oranı (RFO), reel faiz oranı farklılığı (RFOF), reel mevduat stoku (RMS), ticaret haddi, ticaret dengesi, yurtiçi krediler/endüstriyel üretimdir. CART modelinde ise fazladan dönem göstergesi kullanılmıştır.

Çalışmada kullanılan göstergelerden PPBE aşağıdaki şekilde hesaplanmıştır (Hagen ve Hoo, 2003: 4).

$$
P P B E=\left(\frac{\Delta \gamma}{\sigma \Delta \gamma}\right)+\left(\frac{\Delta f}{\sigma \Delta f}\right)
$$

Formüldeki $\Delta y$ Merkez Bankası'nın bankalara verdiği kredilerin toplam mevduata oranındaki değişimi, $\Delta f$ bankalar arası gecelik faiz oranındaki değişimi ve $\sigma$ standart sapmayı göstermektedir. Analizde kullanılan tüm veriler aylıktır ve mevsimsellikten arındırmak amacı ile yıllık yüzde değişimleri alınmıştır. Analizlerde veri ulaşım problemlerinden dolayı analiz dönemi 1990:01-2009:07 ile sınırlandırılmak zorunda kalınmıştır. Reel döviz kuru verileri TCMB veri dağıtım sisteminden (EVDS), diğer verilerde International Financial Statistic Database'den (IFS Database) sağlanmıştır.

\section{UYGULAMALAR}

Aşağıda sırasıyla regresyon ağaçları ve MRD modelleri ile yapılan uygulamalar anlatılmaktadır.

\subsection{Regresyon Ağaçları Modeli}

Çalışmada kriz dönemlerini ifade eden FBE'leri sürekli verilerden oluştuğu için CART modeli içinden regresyon ağaçları kullanılmıştır. Statistica ${ }^{\circledR}$ programı kullanılarak yapılan analizlerde ayırma kriteri olarak LSD safsızlık endeksi, doğruluk sınamasında ise N-katlı çapraz geçerlilik sınaması 10 değeri ile uygulanmıştır. Şekillerdeki ID düğüm numarasını, N gözlem sayısını, Mu bağılı değişken değerlerinin ortalamasını, Var varyansı vermektedir. Düğümlerdeki ortalama değerleri bağımlı değişken olan FBE'nin ortalama değerlerini vermektedir ve mutlak değer olarak kriz olasılığını göstermektedir. Çalışmada kriz dönemleri CART modeli kullanılarak belirlenmiştir. Belirlenen ilk kriz dönemi 1994:1-1994:6'dir ve 6 ay sürmüştür. İkinci kriz dönemi ise 2001:1-2002:1'dir ve 21 ay sürmüştür. Statistica programı tarafından bulunan optimal ağaç, çalışmada kullanılan gösterge sayısının fazla olması nedeniyle çok sayıda düğüme sahiptir ve dolayısıyla anlamlı bir analize imkan tanımayacak derecede karmaşıktır. Bu nedenle Türkiye için Statistica programının oluşturduğu tüm ağaçlar incelenerek makul sayılabilecek bir düğüm sayısına sahip ağaç optimal ağaç olarak seçilmiştir.

Analiz sonuçları Şekil 2 ve Tablo 1'de gösterilmektedir. Analiz sonucuna göre ağacın kök düğümünde 
235 gözlem vardır ve FBE'nin ortalaması 21,39'dur. İlerleyen düğümlerde bu ortalamadan önemli ölçüde gerçekleşecek pozitif sapmalar kriz olasılığının arttığını göstermektedir. FBE'ni en fazla etkileyen göstergenin ticaret dengesi olduğu ve eşik değerinin 10,89 olduğu görülmektedir.

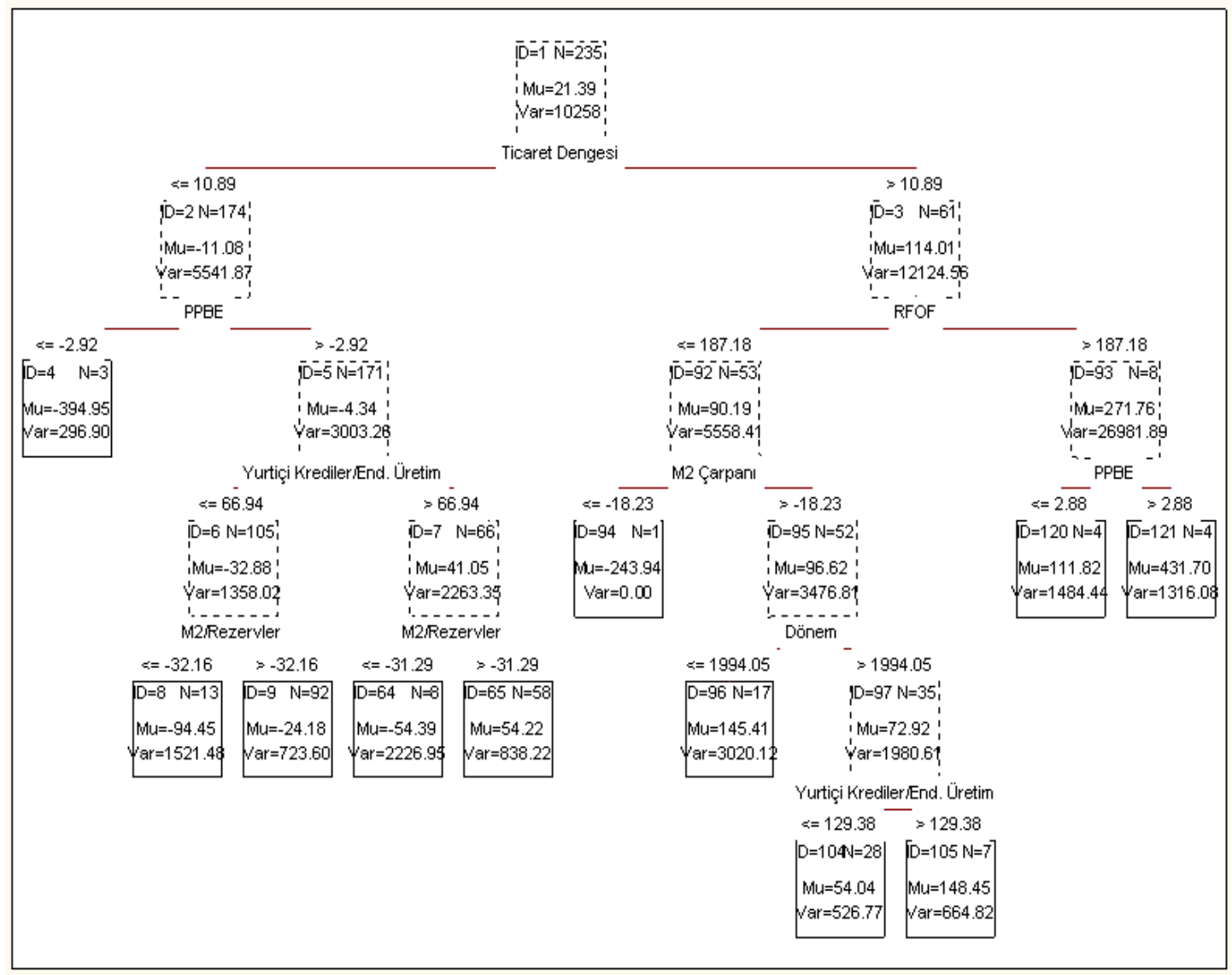

Şekil 2: Optimal Regresyon Ağacı (49 Numaralı Ağaç)

Ticaret dengesindeki artışın 10,89'dan büyük olduğu durumlarda kriz olasılığı 114,01 iken 10,89'dan küçük olduğu durumlarda -11,08'e düşmektedir. Ticaret dengesinin 10,89'dan küçük olduğu durumlarda krizi açıklayan en iyi göstergeler sırası ile yurt içi kredilerin endüstriyel üretime oranı ile M2/rezervlerdir. Yurt içi kredilerin endüstriyel üretime oran'ının 66,94 ve M2/rezervlerin -31,29 değerlerinden büyük olduğu durumlarda kriz olasılığı 54,22'ye çıkmaktadır. Ağacın sağ dalına baktığımızda RFOF'nın 187,18 ve PPBE'nin 2,88 değerinden büyük olduğu durumlarda kriz olasılığı 431,70 gibi yüksek bir rakama ulaşmaktadır. RFOF'nin eşik değeri olan 187,18 değerinden küçük olduğu durumlarda $\mathrm{M} 2$ çarpanındaki bir artışın kriz olasııı̆ını 96.62'ye çıkardığı görülmektedir. M2 çarpanından sonraki alt göstergenin dönem olduğu görülmektedir. 1994 Mayıs'ından önce kriz olasılığı 145,41 iken bu tarihten sonra 72,92'ye düşmektedir. 1994 Mayıs'ından sonra yurt içi kredilerin endüstriyel üretime oranındaki artış kriz olasılığını artırmaktadır. Optimal ağaçta yer almamasına rağmen Statistica programının belirlediği diğer kriz dönemi ise 2001:12002:1 dönemidir. Bu kriz dönemi maksimal ağaçta yer almaktadır. Program Türkiye'de yaşanan Şubat 2001 krizini öngörüde başarılı bulunmuştur.

Tablo 1'de göstergelerin maksimal ağaçtaki önem sırası yer almaktadır. Daha önce de bahsedildiği gibi maksimal ağaç doğruluğu en yüksek ağaç olmasına rağmen oldukça karmaşık bir yapıya sahiptir ve çok fazla sayıda düğüme sahip olduğu için görsel olarak yorumlanması son derece güçtür. Statistica programının bu problem karşısında optimal ağaç belirlemesinin yanında kullanışlı bir diğer aracı da göstergelerin maksimal ağaçtaki önem sırasıdır. Program, maksimal ağacı bir bütün olarak değerlendirerek finansal krizleri açıklamada göstergeleri önem derecesine göre büyükten küçüğe doğru sıralamaktadır. Önem derecesi bir ile sıfır değerleri arasında yer 
almaktadır. Tablo 1 incelendiğinde, optimal ağaçta bulunan göstergelerin maksimal ağaçtaki önem derecesi yüksek göstergeler arasında yer aldığı görülmektedir. Maksimal ağaçtaki önem derecesine göre finansal krizi açıklayan en iyi göstergeler PPBE, yurt içi kredilerin endüstriyel üretime oranı, $\mathrm{M} 2$ /rezervler, ticaret dengesi iken en başarısız göstergeler endüstriyel üretim, ticaret haddi, M2/rezervler (düzey) ve RMS'dir.

Tablo 1: Göstergelerin Önem Derecesi

\begin{tabular}{|l|c|l|c|}
\hline Göstergeler & $\begin{array}{l}\text { Önem } \\
\text { Derecesi }\end{array}$ & Göstergeler & $\begin{array}{l}\text { Önem } \\
\text { Derecesi }\end{array}$ \\
\hline PPBE & $1.00^{*}$ & M2 Çarpanı & $0.45^{*}$ \\
\hline Y. Kred./End. Ür. & $0.88^{*}$ & RFOF & $0.40^{*}$ \\
\hline M2/Rezervler & $0.78^{*}$ & RFO & 0.38 \\
\hline Tic. Dengesi & 0.75 & His. Sen. Fiy. & 0.38 \\
\hline Enflasyon & 0.63 & End. Üretim & 0.37 \\
\hline Dönem & $0.62^{*}$ & Tic. Haddi & 0.34 \\
\hline RDKTS & 0.54 & M2/Rez.(Düz.) & 0.26 \\
\hline Petrol Fiyatı & 0.48 & RMS & 0.23 \\
\hline
\end{tabular}

* Optimal Ağaçta Kullanılan Göstergeler.

\subsection{MRD Modeli}

MRD modelinde verilerin seçimi konusunda literatürde Hendry yaklaşımı olarak belirlenen genelden özele yöntemi uygulanmıştır (Hendry ve Richard, 1983: 3-32). Çok sayıda model denemesi yapılmış, açıklayıcı gücü en yüksek, teorilerle örtüşen ve anlamlı olan model seçilmiştir. MRD modelinde analizler Pc-Give ${ }^{\circledast}$ programı kullanılarak yapılmıştır. Çalışmada rejim sayısını belirlemek için Davies testi yapılmış ve test sonucuna göre iki rejimli MRD modeli kullanılmıştır. ${ }^{3}$ Çalışmada doğrusal olmayan modelleme tekniklerinden MRD modeli kullanılmıştır. Bunun nedeni, Şekil 1'de de görüldüğü gibi kriz dönemlerinin ve istikrarlı dönemlerin elde edildiği FBE'nin birçok yapısal kırılmaya sahip olması ve literatürde genel olarak finansal krizlerinin öngörüsünde doğrusal olmayan modellerden MRD modelinin kullanılıyor olmasıdır. Genelde özele yaklaşımına göre seçilen model aşağıdaki gibidir;

$$
\begin{gathered}
F B E=a_{s_{t}}+\beta_{s_{t}} r d k t s_{t}-\varepsilon_{s_{t}} t h_{t}-\theta_{s_{t}} t d_{t}+ \\
\vartheta_{s_{t}} y k r d_{t}+\rho_{s_{t}} \text { enf } f_{t}+\tau_{s_{t}} m 2_{t}+\varepsilon_{t} \\
s=0,1 \quad \varepsilon_{t} \sim i, i, d, N\left(0 . \sigma_{\varepsilon s_{t}}^{2}\right)
\end{gathered}
$$

Formüldeki rdkts reel döviz kurunun trendden sapmasını, th ticaret haddini, td ticaret dengesini, ykrd yuriçi krediler/endüstriyel üretimi, enf enflasyonu, m2 M2/rezervleri, s rejim sayısını ifade etmektedir.

Bu çalışmada, ele alınan model doğrusal olmayan bir yapıya sahiptir. Modelin doğrusal olmadığına LR (Likelihood Ratio) doğrusallık testi sonucuna göre karar verilmiştir. Bu test, sınırlandırılmış ve sınırlandırılmamış Gaussian log-olabilirlik fonksiyonunu maksimize ederek, iki farklı rejimdeki parametrelerin birbirine eşit olup olmadığını test etmektedir. Sıfır hipotezi her iki rejime ait parametrelerin birbirine eşit, dolayısıyla modelin doğrusal bir yapıda olduğunu, alternatif hipotez ise her iki rejime ait parametrelerin birbirinden farklı olduğunu ve modelin doğrusal olmayan bir yapıda olduğunu göstermektedir (Albero, 2006:7).

Türkiye'ye ilişkin MRD modeli sonuçları Şekil 2, Tablo 2 ve 3'de verilmiştir. Tablo 2'ye göre rejimlerin özelliklerine bakacak olursak; Modelde "rejim 0" finansal krizlerin yaşandığı (FBE'nin yükselme eğilimi gösterdiği); "rejim 1" ise ekonominin istikrarlı olduğu (FBE'nin düşme eğilimi gösterdiği) süreci belirtmektedir. Toplam 222 gözlemin bulunduğu sürecin 13'ü Rejim 0'a; 222'si Rejim 1'e aittir. Rejim 0'ın geçerli olduğu dönemler 1994:2-1994:5, 1995:2-1995:5, 2000:11-2001:2 ve 2002:1-2002:1 dönemleridir. Rejim 0'ın olasılığı 5,53 iken Rejim 1'in olasılığı 94,47'dir. Rejim olasılık matrisinde görüldüğü gibi her iki rejim yüksek bir kalıcılık göstermektedir. Rejim 0'dan Rejim 1'e geçiş olasılığı 0.32 iken Rejim 0'dan Rejim 1'e ge-

\begin{tabular}{|c|c|c|c|c|c|c|c|}
\hline \multicolumn{4}{|c|}{ Rejim Özellikleri } & \multicolumn{2}{|c|}{$\begin{array}{c}\text { Rejim Olasılıkları } \\
\text { Matrisi }\end{array}$} & Kriz Rejimi & İstikrarlı Rejim \\
\hline & $\begin{array}{l}\text { Gözlem } \\
\text { Sayısı }\end{array}$ & Olasılık & Süre & Rejim $0^{*}$ & Rejim 1 & \multirow{3}{*}{$\begin{array}{l}\text { 1994:2 - 1994:5 (4 ay) } \\
\text { 1995:2 - 1995:5 (4 ay) } \\
\text { 2000:11 - 2001:2 (4 ay) } \\
\text { 2002:1-2002:1 (1 ay) }\end{array}$} & \multirow{3}{*}{$\begin{array}{l}\text { 1990:1 - 1994:1 } \\
\text { 1994:6 - 1995:1 } \\
\text { 1995:6 - 2000:10 } \\
2002: 3-2009: 7\end{array}$} \\
\hline Rejim $0^{*}$ & 13 & 5.53 & 3.25 & 0.68 & 0.02 & & \\
\hline Rejim 1 & 222 & 94.47 & 44.4 & 0.32 & 0.98 & & \\
\hline
\end{tabular}
çiş olasıılı̆ı 0.02 'dir.

Tablo 2: Markov Rejim Değişimi Tahmin Sonuçları 
Tablo 3'e göre yurtiçi kredilerin endüstriyel üretime oranı (0) dışında bütün göstergeler istatistikî olarak anlamlı bulunmuştur. Kriz dönemi için, ticaret haddi ve RDKTS göstergelerinin işaretleri beklendiği gibi çıkmamıştır. LR olabilirlik oranına göre model doğrusal değildir. Göstergeleri tek tek yorumlayacak olursak; RDKTS ulusal paranın değerlendiğini gösteren bir göstergedir. Ulusal paranın aşırı değerlenmesi cari işlemler dengesini bozmaktadır. Reel kurdaki artışlar, sermaye kaçışlarını başlattığı için kriz öncesi işaretinin artı (+) olması beklenmektedir. RDKTS'nin işareti beklentiler doğrultusunda çıkmamıştır. Bunun nedeni kriz dönemlerinde gerçekleştirilen devalüasyonların ulusal paranın değerini düşürmesi olabilir. İhracat fiyatlarının ithalat fiyatlarına oranını ifade eden ticaret hadlerindeki kötüleşme, ülkenin ödemeler bilançosu pozisyonunu zayıflatarak kriz olasıı̆ğını artırmaktadır. Bu nedenle kriz öncesi işaretinin eksi olması beklenmektedir. Bu gösterge de beklentilerin aksine artı işaretli çıkmıştır. Ticaret dengesi gerçekleştirilen inracat miktarı ile ithalat miktarı arasındaki farkı ifade etmektedir. Ticaret dengesinin kötüleşmesi devalüasyon beklentilerini artırdığı için kriz öncesinde işaretinin eksi olması beklenmektedir ve analiz sonucuna göre işareti beklenen yönde çıkmıştır.

Yurtiçi kredi hacminin genişlemesi bankacılık sisteminin kırılganlığını göstermektedir. Bu oran genellikle bankacılık krizlerinin erken evrelerinde artmaktadır. Kriz geliştikçe MB finansal sistemi desteklemek için bankalara para enjekte etmektedir. Kriz öncesi dönemde bu göstergenin değerinin artması beklenmektedir ve analiz sonucu beklenen yönde olmuştur.
Tablo 3: Markov Rejim Değişimi Tahmin Sonuçları

\begin{tabular}{|l|l|l|l|l|}
\hline Göstergeler & Katsayı & Std. Hata & t-değ. & Olasılık \\
\hline Sabit (0) & 198.38 & 112.20 & 1.77 & 0.08 \\
\hline Sabit (1) & -63.34 & 8.75 & -7.24 & 0.00 \\
\hline RDKTS(0) & -11.4 & 1.84 & -6.19 & 0.00 \\
\hline RDKTS(1) & -0.65 & 0.31 & -2.11 & 0.04 \\
\hline Ticaret Haddi (0) & 1.38 & 0.14 & 9.72 & 0.00 \\
\hline Ticaret Haddi (1) & 0.29 & 0.03 & 9.93 & 0.00 \\
\hline Ticaret Dengesi (0) & -30.41 & 2.71 & -11.20 & 0.00 \\
\hline Ticaret Dengesi (1) & -2.24 & 0.44 & -5.07 & 0.00 \\
\hline Y.Kred/End.Ür.(0) & 0.78 & 0.79 & 0.99 & 0.32 \\
\hline Y.Kred./End. Ür.(1) & 0.69 & 0.11 & 6.06 & 0.00 \\
\hline Enflasyon(0) & -11.55 & 0.74 & -15.70 & 0.00 \\
\hline Enflasyon(1) & 0.57 & 0.14 & 4.02 & 0.00 \\
\hline M2/Rez.(Düz.)(0) & 267.75 & 22.45 & 11.90 & 0.00 \\
\hline M2/Rez.(Düz.)(1) & 9.11 & 2.28 & 4.00 & 0.00 \\
\hline Olabilirlik Oranı (LR) & 97.62 & & & 0.00 \\
\hline
\end{tabular}

Enflasyon oranları, yüksek nominal faiz oranları ile birlikte hareket etmektedir. Ekonomiyi ve bankacilık sektörünü olumsuz etkileyerek finansal kırılganlığı artırmaktadır. Enflasyonun kriz öncesi artması beklenmektedir. M2/Rezervler, merkez bankasının parasal yükümlülüklerinin artıı̆ını ve bu artış ile birlikte finansal sistemin olası şoklara karşı savunmasız bir duruma düştüğünü ifade etmektedir. M2/Rezervlerde kriz öncesi artış beklenmektedir. Analiz sonucuna göre hem enflasyonun hem de M2/Rezervlerin işaretleri beklenen yöndedir.
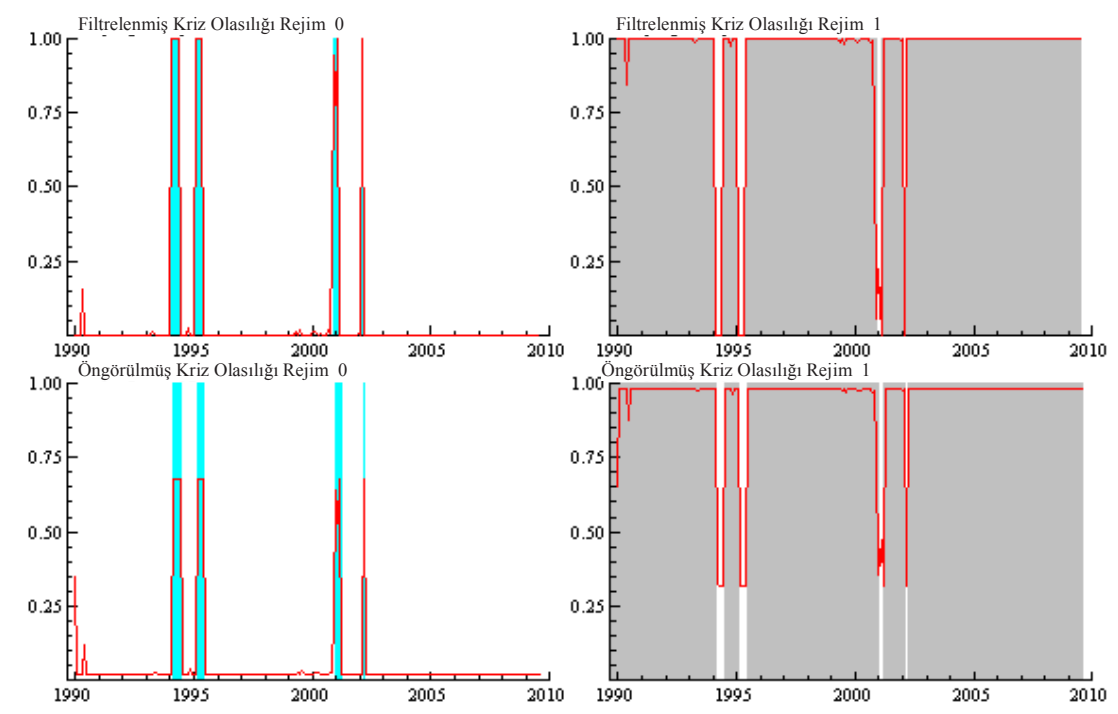
Tablo 3 ve Şekil 2'ye göre, kriz dönemi olarak kabul ettiğimiz rejim 0'a ilk geçiş Şubat 1994 yılında gerçekleşmiş ve model Nisan 1994 krizini iki ay önceden öngörmüştür. Türkiye'deki ikinci rejim geçişi Şubat 1995 'te gerçekleşmiş ve 4 ay sürmüştür. Bu rejim değişiminin sebebinin Aralık 1994 yılında Meksika'da başlayan kriz olduğu düşünülmektedir. Üçüncü rejim değişimi Kasım 2000'de başlamış ve 4 ay sürmüştür. Model, Şubat 2001 krizini öngörmede başarılıdır. 4. son rejim değişimi ise Ocak 2002'deki 1 aylık değişimdir. Bu rejim değişiminin sebebinin ise Ocak 2002'de Arjantin'de meydana gelen kriz olduğu düşünülmektedir. 2002 Arjantin krizi yayılma mekanizması ile özellikle gelişmekte olan ülkeleri etkilemiştir. 4. rejim değişiminin 1 ay gibi çok kısa sürmesinin nedeni krizin Türkiye'de meydana gelen bir kriz olmayıp dış kaynaklı olmasından dolayıdır.

\section{SONUÇ}

Çalışmada regresyon ağaçları ve MRD modelleri ile 1991-2009 döneminde Türkiye'de meydana gelen finansal krizler öngörülmeye çalışılmış ve bu krizlerin belirleyenleri araştırılmıştır. Regresyon ağaçları modelinin sonuçlarını değerlendirdiğimizde şu tespitleri yapabiliriz. Finansal krizleri öngörmede en başarılı bulunan göstergeler PPBE, yurtiçi kredilerin endüstriyel üretime oranı, $\mathrm{M} 2 /$ rezervler, ticaret dengesi ve enflasyondur. Finansal krizleri öngörmede en başarısız olan göstergeler ise M2/rezervler (düzey), RMS, ticaret haddi, endüstriyel üretim ve hisse senedi fiyatıdır. Regresyon ağaçları modeli, Türkiye'de model tarafından belirlenen finansal krizleri öngörmede genel olarak başarılı bulunmuş ve 1994 ve 2001 yıllarındaki krizler öngörülmüştür. Ancak model, 2008 Küresel Finansal Krizini kriz dönemi olarak belirleyememiştir.

MRD modelinde ise finansal krizlerin öngörüsünde en başarılı bulunan göstergeler RDKTS, ticaret haddi, ticaret dengesi, yurtiçi kredilerin endüstriyel üretime oranı, enflasyon ve M2/rezervler (düzey.)'dir. MRD modelinde de regresyon ağaçları modelinde olduğu gibi 1994 ve 2001 yıllarındaki krizler öngörülürken 2008 Küresel Finansal Krizi öngörülememiştir.
Çalışmada finansal kriz dönemlerini belirlemek amacıyla oluşturulan FBE'lerinde 2008 küresel finansal krizi, kriz dönemi olarak yer almamaktadır. Ancak Türkiye'ye ait veriler tekil olarak incelendiğinde para piyasası baskı endeksi, endüstriyel üretim, petrol fiyatı, ticaret dengesi ve reel döviz kurunun trendden sapması göstergelerinin kriz sinyalleri verdiği görülmektedir. Türkiye'de bazı göstergelerin önemli sinyal vermesine rağmen finansal krizlerin öngörülememesi iki nedenden kaynaklanmaktadır. Bunlardan birincisi, oluşturulan finansal baskı endeksleri ile yaşanan kriz dönemlerinin belirlenememesidir. Bu problem daha farklı finansal baskı endeksleri kullanılarak çözülebilir. İkinci neden ise bazı göstergelerde önemli değişiklikler olsa da göstergelerin genelinde kriz sinyali oluşturabilecek kadar bir hareketlenmenin olmamasıdır.

Finansal krizlerin öngörüsünde modellere göre başarılı göstergeler farklılık gösterse de ticaret dengesi, yurtiçi kredilerin endüstriyel üretime oranı, enflasyon gibi göstergeler genelde başarılı bulunmuşlardır. Bu nedenle öncü göstergelerin belirlenmesinde ve finansal krizlerin öngörüsünde daha başarılı sonuçlara ulaşmak için ülke gruplarına yönelik analizler yerine tek ülke bazlı analizler yapılması ve birden fazla modelin bir arada kullanılarak sonuçların güvenilirliğinin artırıması tarafımızca önerilmektedir. Ekonomi otoritelerinin ve özellikle finansal istikrar amacına yönelen merkez bankaları tarafından gerekli tedbirlerin zamanında alınabilmesi için, ülkelerin genelinde başarılı bulunan göstergeler ile her bir ülke için ayrı ayrı başarılı bulunan göstergelerin sürekli takip edilmesi finansal krizlere karşı önemli bir iktisat politikası uygulama seçeneğini oluşturacaktır. 


\section{SON NOTLAR}

${ }^{1}$ Gini indeksi bir düğümde yer alan verilerin bağımlı değişken değerleri arasındaki farklılığı ölçmektedir. Eğer düğümdeki verilerin tümü aynı kategoriye ait ise gini indeksi maksimum homojenliğe ulaşarak sıfır değerini almaktadır. Bu durumda daha fazla ayırma yapılmasına gerek yoktur. LSD ise regresyon ağaçlarında düğümlerin homojenliğini ölçmek için kullanılmaktadır ve en küçük kareler yöntemine benzemektedir. Eğer bir düğümde yer alan verilerin bağımlı değişken değerleri birbirine çok yakınsa LSD değeri sıfıra yaklaşmakta ve o düğümün homojenliği artmaktadır.

2 Bkz. Sinyal yaklaşımı için Kaminsky vd., 1998; Kaminsky ve Reinhard, 1999; Berg ve Pattilo, 1998; IMF, 1998; Edison, 2000; Peng ve Bojana, 2008; Davis ve Karim, 2008; Logit-Probit modeli için Frankel ve Rose, 1996; Eichengreen vd., 1996; Kruger vd., 1998; Zinkovskaya, 2008; MRD modeli için Abiad, 1999;
Mariano vd., 2004, Arias, 2005; Knedlik, 2006; Önder ve Çeşmeci, 2008; Yapay sinir ağları modeli için Nag ve Mitra, 1999; Oh vd., 2006; Akel ve Bayramoğlu 2008; Fioramanti, 2006; Peltonen, 2006; Faktör analizi için Işık vd., 2004; Diskriminant analizi için Erkekoğlu ve Bilgili, 2005; Sürekli kriz modeli için Vlaar, 1999.

${ }^{3}$ Yapılan Davies sınır testinde iki farklı olasılık test edilmiştir. İlk olasılık, bir rejime karşılık iki rejimin varlığıdır (H0 hipotezi: bir rejimli MRD modeli, H1 hipotezi: iki rejimli MRD Modeli). Bir rejimin varlığı hipotezi reddedildiği için(olasılık değeri: 0.00) iki rejimin varlığı kabul edilmiştir. Ancak iki rejime karşılık üç rejimin varlığ1 test edildiğinde ise (H0 hipotezi: iki rejimli MRD modeli, H1 hipotezi: üç rejimli MRD Modeli), üç rejimin varlığı reddedilmiş (olasılık değeri: 0.12) ve iki rejimli modelin analizi uygun görülmüştür

\section{KAYNAKLAR}

Abiad, A. (2003) "Early Warning Systems for Currency Crises: A Regime-Switching Approach" IMF Working Paper, No:03(32).

Akel, V. ve Bayramoğlu, M.F. (2008) “Kriz Dönemlerinde Yapay Sinir Ağları ile Finansal Öngörüde Bulunma: İMKB 100 Endeksi Örneği” Balıkesir University Bandırma Faculty of Administrative Sciences, International Capital Flows and Emerging Markets Symposium, April 24-27, Balıkesir.

Albero, C. (2006) "Structural Breakpoint Tests in a Markov-Switching Model: An Empirical Application to the EMU Member Countries" http://www.econ. upenn.edu/ fuentesa/emu_last.pdf, (10.08.2012)

Altay, N.O. (2002) "Uluslararası Finansal Piyasaların Gelişmesi Karşısında Türk Finans Piyasalarında Yenilenme" Süleyman Demirel Üniversitesi VI. Türkiye Finans Eğitimi Sempozyumu, Aralık 11-14, Isparta.

Altay, N.O. (2011) "Cumhuriyetten Günümüze Türkiye Ekonomisi ve Türkiye Avrupa Birliği İlişkileri 1923-2011” Ege Üniversitesi Kadın Sorunları Uygulama ve Araştırma Merkezi.

Arias, G. ve Erlandss, U.G. (2005) "Improving Early Warning Systems With a Markov Switching Model - An Application to South-East Asian Crises"C.E.F.I. Working Paper Series, No:0502.

Aydoğuş, O. (2009) “2008-09 (?) Küresel Krizi’nden Geçerken Türkiye Ekonomisi Üzerine Bazı Gözlem ve Değerlendirmeler" Tisk Akademi, Özel Sayı 2:27-50.
Berg, A. ve Pattillo, C. (1998) "Are Currency Crises Predictable? A Test” IMF Working PaperSeries , No:154.

Breiman, L., Friedman, J.H., Olshen, R.A. ve Stone, J.C. (1984) Classification and Regression Trees, Monterey California, Wadsworth Inc.

Brunetti, C., Mariano, R.S., Scotti C. ve Tan A. H.H. (2007) "Markov Switching GARCH Models of Currency Turmoil in Southeast Asia Board of Governors of the Federal Reserve System" International Finance Discussion Papers, No:889.

Burkard, O. ve Coudert, V. (2000) "Currency Crises in the Emerging Economies" Banque de France Bulletin, No:82.

Chamon, M., Manasse, P. ve Prati, A. (2007) "Can We Predict the Next Capital Account Crisis?” IMF Staff Papers, No:54(2).

Çeşmeci, Ö. ve Önder, A.Ö. (2008) “Determinants of Currency Crises in Emerging Markets" Emerging Markets Finance \& Trade, 44(5):54-67.

Davies, R. (1987) "Hypotesis Testing When a Nuisance Parameter is Present Only Under the Alternative" Biometrika, 74(1):33-43.

Davis, E.P. ve Karim, D. (2008) "Could Early Warnin Systems Have Helped to Sub-Prime Crisis?" National Institute Economic Review, 206:1-13.

Duttagupta, R. ve Cashinl, P. (2008) “The Anatomy of Banking Crises” IMF Working Papers Series, No:93. 
Edison, H.J. (2000) "Do Indicators of Financial Crises Work? An Evaluation of An Early Warning System" Board of Governors of the Federal Reserve System, International Finance Discussion Papers, No:675.

Eichengreen, B., Rose, A. ve Wyplosz, C. (1995) "Exchange Market Mayhem: The Antecedents and Aftermath of Speculative Attacks" Economic Policy, 21:251-312.

Eichengreen, B., Rose, A. ve Wyplosz, C. (1996) "Contagious Currency Crises" NBER Working Papers Series, No:5681.

Erkekoğlu, H. ve Bilgili, E. (2005) "Parasal Krizlerin Tahmin Edilmesi: Teori ve Uygulama" Erciyes Üniversitesi İ.I.B.F. Dergisi, 24:15-35.

Fioramanti, M. (2006) "Predicting Sovereign Debt Crises Using Artificial Neural Networks: A Comparative Approach" Istituto Di Studi E Analisi Economica Working Paper Series, No: 72.

Frankel, J. ve Rose, A. (1996) "Currency Crashes in Emerging Markets: Emprical Indicators" NBER Working Papers Series, No:5437.

Gosh, S. ve Gosh, A.R. (2003) "Structural Vulnerabilities and Currency Crises" IMF Staff Papers, No:50(3).

Hagen, J. ve Hoo, T. (2004) "Money Market Pressure and Determinants of Banking Crises" ZII Working Paper, No:20.

Hamilton, J. D. (1989) "A New Approach to Economic Analysis of Nonstationary Time Series and the Business Cycle" Econometrica, 57(2):357-384.

Hamilton, J. D. (1990) "Analysis of Time Series Subject to Changes in Regime" Journal of Econometrics, 45(1/2):39-70.

Hamilton, J. D. (1994) Time Series Analysis, New Jersey, Princeton Universty Press.

IMF (1998) "Financial Crises: Characteristics and Indicators of Vulnerability" World Economic Outlook, 4:74-97.

IMF (2010) International Financial Statistics Database IFS http://www.imf.org/external/data.htm, (06.08.2010)

Işık, S., Duman, K. ve Korkmaz, A. (2004) “Türkiye Ekonomisinde Finansal Krizler: Bir Faktör Analizi Uygulaması" Dokuz Eylül Üniversitesi, Dokuz Eylül Üniversitesi İktisadi ve İdari Bilimler Fakültesi Dergisi, 19(1):45-69.

Kaminsky, G., Lizondo, S. ve Reinhart, C. (1998) "Leading Indicators of Currency Crises" Policy Research Working Paper, No.1852.
Kaminsky, G.L. ve Reinhart, C. (1999) "The Twin Crises: The Causes of Banking and Balance of Payments Problems" American Economic Review, 89(3):1-28.

Kasman, A. (2003) "Banking Efficiency During the Financial Crisis Period” ISE Review, 7: 25-26.

Knedlik, T. ve Scheufele, R. (2007) "Three methods of forecasting currency crises: Which made the run in signaling the South African currency crisis of June 2006?," Halle Institute for Economic Research, IWH Discussion Papers, No:17.

Krkoska, L. (2000) "Assensing Macroeconomic Vulnerability in Central Europe" Eurpean Bank for Reconstruction and Development, Working Paper Series, No:52.

Kruger, M., Patrick N. O. ve Page, J. (1998) "Fundamentals, Contagion and Currency Crises: An Empirical Analysis" Bank of Canada Working Paper, No:98-10.

Manasse, P., Roubini, N. ve Schimmelpfennig, A. (2003) "Predicting Sovereign Debt Crises" IMF Working Paper Series, No:221.

Mariano, R.S., Gultekin, B.N., Ozmucur, S., Shabbir, T. ve Alper, C.E. (2004) "Prediction of Currency Crises: Case of Turkey" Review of Middle East Economics and Finance, 2(2):87-107.

Nag, A.K. ve Mitra, A. (1999) "Neural Networks and Early Warning Indicators of Currency Crisis" Reserve Bank of India Occasional Papers, 20(2):133-222.

Nisbet, R., Elder, J. ve Miner, G. (2009) Handbook of Statistical Analysis and Data Mining Applications, USA, Academic Press is an Imprint of Elsevier.

Oh, K.J., Kim, T.Y. ve Kim, C. (2006) "An Early Warning System for Detection of Financial Crisis Using Fnancial Market Volatility" Expert Systems, 23(2):83-98.

Özatay, F. (2011) Parasal İktisat: Kuram ve Politika, Ankara, Efil Yayınları.

Peltonen, T.A. (2006) "Are Emerging Market Currency Crises Predictable? A Test" Europen Central Bank Working Paper Series, No:571.

Peng, J. ve Bojana, C. (2008) "China’s Vulnerability to Currency Crisis: A KLR Signals Approach” China Economic Review, 19:138-151.

Statsoft, (2011) "Electronic Statistic Textbook" http://www.statsoft.com/textbook/, (05.07.2011)

Şahin, H. (2002) Türkiye Ekonomisi, Bursa, Ezgi Kitabevi.

TCMB (2011) Elektronik Veri Dağıtım Sistemi, http://evds.tcmb.gov.tr/cbt.html, (05.06.2011) 
Togan, S. (2009) "Küresel Kriz ve Türkiye" TISK Akademi, Özel Sayı II.

Vlaar, P.J.G. (1999) "Currency Crisis Models For Emerging Markets" De Nederlandsche Bank Econometric Research and Special Studies Department, No:595.
Zinkovskaya, E. (2008) "Determinants of Financial Crises in Russia and Other Transition Economies: An Empirical Test" Japanese Journal of Comparative Economics, 45(2):1-18. 